\title{
Special Issue on Nanofluids and Their Applications
}

\author{
Guan Heng Yeoh ${ }^{1, *(1)}$ and Sherman Cheung ${ }^{2}(\mathbb{D}$ \\ 1 Mechanical and Manufacturing Engineering, University of New South Wales, Sydney NSW 2052, Australia \\ 2 Mechanical and Automotive Engineering, RMIT University, Bundoora VIC 3083, Australia; \\ chipok.cheung@rmit.edu.au \\ * Correspondence: g.yeoh@unsw.edu.au; Tel.: +61-2-9385-4099
}

Received: 29 March 2019; Accepted: 1 April 2019; Published: 9 April 2019

\section{Introduction}

Nanofluids can be considered as engineered colloidal suspensions of nanometer-sized particles in a base fluid of water, ethylene glycol, or oil. Such fluids are fundamentally characterized by Brownian agitation or diffusion, in which they can then overcome the settling motion of the so-called nanoparticles due to gravity. So long as the individual nanoparticles remain finely dispersed or the particle agglomerates remain small enough (usually $<100$ nanometers) in order to avoid large particle agglomerates from settling within the colloidal suspension, stable nanofluids are theoretically possible. Maintaining this small size is, however, the greatest challenge, since it is well understood that nanoparticles have a tendency to cluster or agglomerate when they come into contact with each other.

Nanofluids are extensively applied and utilized in a wide variety of engineering applications. For heat transfer processes, this has been primarily driven by the potential of developing fluids with significantly-increased conductive and convective heat transfer properties. Specific emphasis in boiling phenomena and absorption and conversion of radiation are some examples of the possible utilizations of nanofluids. Other non-heat transfer applications that have considered the use of nanofluids include emerging synthesis techniques, mass transport, optics, consumer goods, electronics, and surfaces and catalysts.

\section{Current Advances in the Applications of Nanofluids}

This special issue was developed to focus on the latest research on relevant topics, and more importantly, to address pertinent challenging issues in the utilization of nanofluids. There were 50 papers submitted to this special issue, and 17 papers were accepted. Revisiting the many contributions to the special issue, several key aspects of nanofluids are addressed.

H. M. Ali, H. Babr, T. R. Shah, M. U. Sajid, M. A. Qasim, and S. Javed [1] present a review on the preparation of $\mathrm{TiO}_{2}$, which has a unique thermal property, to be dispersed in base fluid, resulting in the possible use of these types of nanofluids for heat transfer applications.

H. Khan, M. Haneef, Z. Shah, S. Islam, W. Khan, and S. Muhammad [2] have performed numerical simulations for the combined effect of magnetic and electric field and thermal radiations on the unsteady flow of Maxwell nanofluid. The physical significance of the problem was investigated by the sensitivity analysis of a range of dimensionless parameters, including the Nusselt, Sherwood, Prandtl, and Schmidt numbers, affecting the flow and thermal characteristics of the nanofluid.

F. Hassain, R. Ellahi, and A. Zaeshan [3] focused on the consideration of the base fluid containing nanosized-Hafnium particles in possible engineering applications for nozzle or diffuser types of injectors in automobiles, to improve performance and reduce fuel consumption.

S. Abu Bakar, N. M. Arigin, F. M. Ali, N. Bachok, R. Nazar, and I. Pop [4] studied the different groupings of a variety of nanoparticles comprising $\mathrm{Cu}, \mathrm{Al}_{2} \mathrm{O}_{3}$, and $\mathrm{TiO}_{2}$, which affect the mixed 
convection boundary layer flow with thermal radiation over a permeable vertical cylinder. $\mathrm{Al}_{2} \mathrm{O}_{3}$ and $\mathrm{TiO}_{2}$ nanoparticles were found to separate the boundary layer more rapidly than $\mathrm{Cu}$ nanoparticles.

Y. Lv, Y. Ge, L. Wang, Z. Sun, Y. Zhou, M. Huang, C. Li, J. Yuan, and B. Qi [5] demonstrated the effects of different nanoparticles, including conductive $\mathrm{Fe}_{3} \mathrm{O}_{4}$, semi-conductive $\mathrm{TiO}_{2}$, and insulating $\mathrm{Al}_{2} \mathrm{O}_{3}$ on the pre-breakdown and breakdown properties of transformer oil. Results attained indicated a clear and notable impact of the breakdown strength and streamer production characteristics of transformer oil by the different nanoparticle materials. The type of nanoparticle materials has a notable impact on breakdown strength and streamer propagation characteristics of transformer oil.

N. Najib, N. Bachok, N. M. Arifin, and F. M. Ali [6] developed a model to comprehensively study a stretching or shrinking sheet of nanofluid and carried out stability analysis of a steady stagnation-point flow under the influence of slip, Soret, and Duffor effects.

K. Raslan, S. Mohammadain, M. Abdel-wahed, and E. M. Abedel-aal [7] utilized a weak concentration micropolar nanofluid model to numerically investigate the cooling process of a moving surface. The presence of $\mathrm{Cu}$ nanoparticles in water was found to increase the rate of heat transfer for the non-Newtonian boundary layer when compared to Newtonian fluids.

S. N. A. Salleh, N. Bachok, N. M. Arifin, F. M. Ali, and I. Pop [8] predicted that the fluid flow and heat transfer analysis of a mixed convection boundary layer flow past a moving vertical thin needle in a nanofluid would consist of $\mathrm{Cu}$ nanoparticles. Effects of parameters, such as velocity ratio, mixed convection, nanoparticle volume fraction, and needle size, were parametrically studied.

Y. Li, Y. Paan and X. Zhao [9] measured and quantified the slip length of liquid-solid micro/nano fluid flow utilizing the atomic force microscopy. Such an approach allows a description of the drainage of thin liquid film between the particle and surface with realistic roughness.

R. Abhishek, A. A. Hamouda, and A. Ayoub [10] studied the adsorption of Silica nanoparticles being dispersed in different brines of chalk surfaces and their effect on fluid/rock interaction. The attained results demonstrated that a small amount of Silica nanoparticles can improve the performance of low salinity floods.

A. Jamaludin, R. Nazar, and I. Pop [11] performed a numerical study considering two types of nanofluids, $\mathrm{Cu}$-water and Ag-water, for the problem of magnetohydrodynamic mixed convection flow of nanofluids over a permeable vertical stretching/shrinking sheet with slip conditions. It was revealed that Ag-water nanofluid displayed better enhancement for heat transfer when compared to that for $\mathrm{Cu}$-water nanofluid.

X. Gu, V. Timchenko, G. H. Yeoh, L. Dombrovsky, and R. Taylor [12] investigated the plasmonic resonant absorption of gold nanorod clusters in the Near Infrared (NIR) wavelength. This study revealed that particle clustering of nanorods should be considered for possible hyperthermia treatments.

H. J. Kim and B. Jo [13] focused on the use of the nanofluid comprising the base fluid of a binary carbonate molten sate mixture and graphite nanoparticles for thermal energy storage application. It was observed that the specific heat of the nanofluid was significantly enhanced by the presence of the graphite nanoparticles.

F. Saba, N. Ahmed, U. Khan, A. Waheed, M. Rafiq, and S. T. Mohyud-Din [14] focused on the investigation of different shapes of $\mathrm{Cu}, \mathrm{Al}_{2} \mathrm{O}_{3}$ nanoparticles, namely plaetelet, cylinder, and brick-shaped particles, affecting the flow and heat transfer characteristics of nanofluid in a rectangular channel. Platelet nanocomposites were found to provide a better heat transfer ability when compared to other shapes.

N. F. Dzulkifli, N. Bachok, N. A. Yacob, N. M. Arifin, and H. Rosali [15] performed a stability analysis of unsteady stagnation-point flow and heat transfer over a permeable exponential stretching or shrinking sheet via the nanofluid model proposed by Tiwari and Das [16], with the base fluid being water filled with three different nanoparticles of $\mathrm{Cu}, \mathrm{Al}_{2} \mathrm{O}_{3}$, and $\mathrm{TiO}_{2}$.

G. Sekrani and S. Poncet [17] reviewed the possible use of ethylene- and propylene-glycol based nanofluids for applications in various thermal systems. These nanofluids can be applied by lowering 
the freezing point to prevent ice formation, such as in refrigeration systems, or pushing beyond the boiling point, such as in radiators or heat exchangers.

A. Abidi. Z. Raizah, and J. Madiouli [18] carried out a three-dimensional numerical investigation to determine the effect of a uniform magnetic field on the heat and mass transfer and fluid flow in a cavity filled with a nanofluid of $\mathrm{Al}_{2} \mathrm{O}_{3}$ nanoparticles. Relevant parameters, such as Rayleigh number, Hartmann number, buoyancy ratio, volume fraction, and vortex viscosity on flow structure and heat were analyzed.

\section{Future Advances in the Applications of Nanofluids}

Although this special issue has been closed, more in-depth research in the applications of nanofluids is expected. Given the findings thus far, there remain many challenges to better understand the underlying mechanisms that lead to unprecedented thermal transport phenomena. Long-term physically and chemically stable nanofluids are required, and the anomalously high transport properties of nanofluids require immediate resolution.

Acknowledgments: This issue would not have been possible without the contributions of various talented authors, hardworking and professional reviewers, and the dedicated editorial team of Applied Sciences. Congratulations to all authors who have contributed to this special issue-no matter what the final decisions of the submitted manuscripts were, the feedback, comments and suggestions provided by the reviewers and editors helped the authors to improve their papers. We would like to take this opportunity to express our sincere gratitude to all reviewers. Finally, we would like to give our sincere thanks to the editorial team of Applied Sciences.

\section{References}

1. Ali, H.M.; Babar, H.; Shah, T.R.; Sajid, M.U.; Qasim, M.A.; Javed, S. Preparation Techniques of $\mathrm{TiO}_{2}$ Nanofluids and Challenges: A Review. Appl. Sci. 2018, 8, 587.

2. Khan, H.; Haneef, M.; Shah, Z.; Islam, S.; Khan, W.; Muhammad, S. The Combined Magneto Hydrodynamic and Electric Field Effect on an Unsteady Maxwell Nanofluid Flow over a Stretching Surface under the Influence of Variable Heat and Thermal Radiation. Appl. Sci. 2018, 8, 160. [CrossRef]

3. Hussain, F.; Ellahi, R.; Zeeshan, A. Mathematical Models of Electro-Magnetohydrodynamic Multiphase Flows Synthesis with Nano-Sized Hafnium Particles. Appl. Sci. 2018, 8, 275. [CrossRef]

4. Abu Bakar, S.; Arifin, N.M.; Md Ali, F.; Bachok, N.; Nazar, R.; Pop, I. A Stability Analysis on Mixed Convection Boundary Layer Flow along a Permeable Vertical Cylinder in a Porous Medium Filled with a Nanofluid and Thermal Radiation. Appl. Sci. 2018, 8, 483. [CrossRef]

5. Lv, Y.; Ge, Y.; Wang, L.; Sun, Z.; Zhou, Y.; Huang, M.; Li, C.; Yuan, J.; Qi, B. Effects of Nanoparticle Materials on Prebreakdown and Breakdown Properties of Transformer Oil. Appl. Sci. 2018, 8, 601. [CrossRef]

6. Najib, N.; Bachok, N.; Arifin, N.M.; Ali, F.M. Stability Analysis of Stagnation-Point Flow in a Nanofluid over a Stretching/Shrinking Sheet with Second-Order Slip, Soret and Dufour Effects: A Revised Model. Appl. Sci. 2018, 8, 642. [CrossRef]

7. Raslan, K.; Mohamadain, S.; Abdel-wahed, M.; Abedel-aal, E.M. MHD Steady/Unsteady Porous Boundary Layer of $\mathrm{Cu}-$ Water Nanofluid with Micropolar Effect over a Permeable Surface. Appl. Sci. 2018, 8, 736. [CrossRef]

8. Salleh, S.N.A.; Bachok, N.; Arifin, N.M.; Ali, F.M.; Pop, I. Stability Analysis of Mixed Convection Flow towards a Moving Thin Needle in Nanofluid. Appl. Sci. 2018, 8, 842. [CrossRef]

9. Li, Y.; Pan, Y.; Zhao, X. Measurement and Quantification of Effective Slip Length at Solid-Liquid Interface of Roughness-Induced Surfaces with Oleophobicity. Appl. Sci. 2018, 8, 931. [CrossRef]

10. Abhishek, R.; Hamouda, A.A.; Ayoub, A. Effect of Silica Nanoparticles on Fluid/Rock Interactions during Low Salinity Water Flooding of Chalk Reservoirs. Appl. Sci. 2018, 8, 1093. [CrossRef]

11. Jamaludin, A.; Nazar, R.; Pop, I. Three-Dimensional Magnetohydrodynamic Mixed Convection Flow of Nanofluids over a Nonlinearly Permeable Stretching/Shrinking Sheet with Velocity and Thermal Slip. Appl. Sci. 2018, 8, 1128. [CrossRef]

12. Gu, X.; Timchenko, V.; Heng Yeoh, G.; Dombrovsky, L.; Taylor, R. The Effect of Gold Nanorods Clustering on Near-Infrared Radiation Absorption. Appl. Sci. 2018, 8, 1132. [CrossRef] 
13. Kim, H.J.; Jo, B. Anomalous Increase in Specific Heat of Binary Molten Salt-Based Graphite Nanofluids for Thermal Energy Storage. Appl. Sci. 2018, 8, 1305. [CrossRef]

14. Saba, F.; Ahmed, N.; Khan, U.; Waheed, A.; Rafiq, M.; Mohyud-Din, S.T. Thermophysical Analysis of Water Based $\left(\mathrm{Cu}-\mathrm{Al}_{2} \mathrm{O}_{3}\right)$ Hybrid Nanofluid in an Asymmetric Channel with Dilating/Squeezing Walls Considering Different Shapes of Nanoparticles. Appl. Sci. 2018, 8, 1549. [CrossRef]

15. Dzulkifli, N.F.; Bachok, N.; Yacob, N.A.; Md Arifin, N.; Rosali, H. Unsteady Stagnation-Point Flow and Heat Transfer Over a Permeable Exponential Stretching/Shrinking Sheet in Nanofluid with Slip Velocity Effect: A Stability Analysis. Appl. Sci. 2018, 8, 2172. [CrossRef]

16. Tiwari, R.K.; Das, M.K. Heat transfer augmentation in a two-sided lid-driven differentially heated square cavity utilizing nanofluids. Int. J. Heat Mass Transf. 2007, 50, 2002-2018. [CrossRef]

17. Sekrani, G.; Poncet, S. Ethylene- and Propylene-Glycol Based Nanofluids: A Litterature Review on Their Thermophysical Properties and Thermal Performances. Appl. Sci. 2018, 8, 2311. [CrossRef]

18. Abidi, A.; Raizah, Z.; Madiouli, J. Magnetic Field Effect on the Double Diffusive Natural Convection in Three-Dimensional Cavity Filled with Micropolar Nanofluid. Appl. Sci. 2018, 8, 2342. [CrossRef]

(C) 2019 by the authors. Licensee MDPI, Basel, Switzerland. This article is an open access article distributed under the terms and conditions of the Creative Commons Attribution (CC BY) license (http://creativecommons.org/licenses/by/4.0/). 